\title{
PROPAGAÇÃO VEGETATIVA DE ÁRVORES SELECIONADAS DE Eucalyptus cloeziana F. Muell. POR ESTAQUIA ${ }^{1}$
}

\author{
Fernanda Daniele de Almeida ${ }^{2}$, Aloisio Xavier ${ }^{3}$ e José Maria Moreira Dias ${ }^{4}$
}

\begin{abstract}
RESUMO - Este trabalho teve como objetivo avaliar a eficiência do enraizamento adventício em estacas extraídas de brotações obtidas por meio da decepa da árvore, anelamento do caule e indução de brotações epicórmicas em galhos podados de árvores de Eucalyptus cloeziana, bem como a influência do AIB no enraizamento adventício dessas estacas. Foram utilizadas brotações de cepas de 3 e 5 árvores de 5 e 15 anos de idade, respectivamente, para o resgate por brotações de cepas. Para o anelamento do caule, foram utilizadas árvores de 5, 15 e 20 anos de idade, enquanto para o resgate por galhos podados as árvores utilizadas eram de 20 anos de idade. A indução de brotações em cepas mostrou melhores resultados para as árvores selecionadas com 5 anos de idade, em relação àquelas de 15 anos. No caso das estacas advindas das árvores de 5 anos de idade, a nãoutilização de AIB proporcionou, para a maioria das características avaliadas, melhores respostas, ao passo que para as de 15 anos de idade a utilização de AIB apresentou melhor enraizamento. Quanto à formação de brotos induzidos em galhos podados e anelamento de caule, essas técnicas se mostraram eficientes na indução de brotações, porém as estacas obtidas não apresentaram resposta ao enraizamento adventício. De forma geral, o resgate por brotações de cepas mostrou-se mais viável em relação às demais técnicas estudadas, tanto pelo maior número de brotações emitidas quanto pela sua capacidade de enraizamento.
\end{abstract}

Palavras-chave: Clonagem, enraizamento de estacas e propagação clonal.

\section{VEGETATIVE PROPAGATION OF SELECTED Eucalyptus cloeziana F. Muell. TREES THROUGH CUTTING TECHNIQUE}

\begin{abstract}
The aim of this study was to evaluate the efficiency of adventitious rooting in cuttings of shoots obtained from tree severance, stem ringing and induction of epicormic shoots on pruned branches of Eucalyptus cloeziana trees, as well as the influence of IBA on the adventitious rooting of the same cuttings. Stump shoots were used from three and five trees, of 5 and 15 years old respectively. Trees of 5, 15 and 20 years old were used for the stem ringing, and 20-year-old trees were used for the delivery by means of pruned branches. Induction of stump shoots showed better results for the selected 5-year-old trees than for the 15-year-old ones. Cuttings originating from 5-year-old trees gave better results without IBA, while those originating from the 15-year-old trees presented better rooting when IBA was used. Shoot formation induced on pruned branches and through stem ringing were considered efficient techniques for shoot induction. The obtained cuttings, however, did not produce adventitious rooting. In general, delivery by stump shoots was shown to be a more viable technique when compared to the other techniques studied, both by the higher number of shoots emitted and their superior rooting capacity.
\end{abstract}

Keywords: Cloning, rooting of cuttings and clonal propagation.

\footnotetext{
${ }^{1}$ Recebido em 10.11.2006 e aceito para publicação em 11.02.2007.

${ }^{2}$ Engenheira Florestal, M.S. E-mail: <fdalmeidaufv@yahoo.com.br>.

${ }^{3}$ Departamento de Engenharia Florestal da UFV. E-mail: <xavier@ufv.br>.

${ }^{4}$ Departamento de Fitotecnia da UFV. E-mail: <jmmdias@ufv.br>.
} 


\section{INTRODUÇÃO}

Dentre os métodos de propagação vegetativa, a estaquia constitui uma das técnicas cujos princípios já estão bem conhecidos para espécies de Eucalyptus, tendo, portanto, ampla adoção na clonagem de árvores desta espécie, o que permitiu o desenvolvimento da silvicultura clonal de forma intensiva em diversas partes do mundo (XAVIER, 2002). A estaquia é, ainda, a técnica da qual se têm o maior domínio e conhecimento científico, representando um dos maiores avanços tecnológicos na área florestal. No entanto, esta técnica apresenta algumas limitações no que se refere à propagação de material adulto, devido ao grau de maturação dos propágulos, levando à redução da competência ao enraizamento adventício em alguns clones (ASSIS, 1997). Esse problema é particularmente sério em espécies que já apresentam baixa predisposição ao enraizamento, como o Eucalyptus cloeziana (ROTUNDO, 1993; ALFENAS et al., 2004).

Em programa de silvicultura clonal, a seleção da árvore superior é geralmente realizada na fase adulta. Nessa seleção, o primeiro passo constitui a obtenção de brotações com maior aptidão ao enraizamento adventício. Assim, Bonga e Von Aderkas (1992) consideraram que, dentro de uma mesma árvore, existem zonas que mantêm por mais tempo a juvenilidade e são suscetíveis de serem estimuladas para a produção de material vegetativo fisiologicamente juvenil. Segundo Zobel e Talbert (1987), essas zonas com maior juvenilidade são aquelas situadas mais próximas à base da árvore, aumentando-se o grau de maturação à medida que se aproxima do ápice da planta.

O conhecimento do fenômeno da retenção da juvenilidade nos tecidos da base do caule de plantas provenientes de sementes permitiu o estabelecimento do primeiro modelo básico, já amplamente aplicado à clonagem de plantas adultas de difícil enraizamento, como algumas espécies de Eucalyptus e macieira (ASSIS e TEIXEIRA, 1998). Segundo esses autores, esse modelo consiste na obtenção de propágulos de brotações surgidas na base da planta, principalmente como resultado da utilização de artifícios, como injúrias mecânicas nas raízes, anelamento na base do caule, poda drástica a poucos centímetros do colo e aplicação de substâncias reguladoras de crescimento, entre outras.

Dentre as formas de resgate para a clonagem de árvores adultas, a mais comumente utilizada pelas empresas florestais é a decepa da árvore para a indução de brotações basais. As brotações emitidas nas cepas possuem características morfológicas e fisiológicas de plantas juvenis, o que é de fundamental importância para a recuperação da competência ao enraizamento adventício (ALFENAS et al., 2004).

Outras formas de indução de brotações em árvores para a clonagem podem ser eficientes na obtenção de estacas mais aptas ao enraizamento, como o anelamento de caule e o uso do fogo, desde que aplicados em zonas com maior retenção da juvenilidade. A indução de brotações epicórmicas a partir de galhos podados e a enxertia constituem-se também em alternativas na obtenção de brotações destinadas ao resgate vegetativo de árvores selecionadas, porém devem ser utilizadas de forma criteriosa, uma vez que usam tecidos que, devido à sua posição na árvore, podem estar fisiologicamente maduros, comprometendo o enraizamento adventício da brotação emitida, além da influência no comportamento silvicultural do clone no plantio futuro.

A técnica de micropropagação tem sido aplicada, sobretudo, no rejuvenescimento de clones de interesse comercial, principalmente os que têm maiores dificuldades de propagação clonal devido ao grau de maturação dos propágulos utilizados (ASSIS et al., 1992; BONGA e VONADERKAS, 1992; HACKETT e MURRAY, 1993; XAVIER e COMÉRIO, 1996; XAVIER et al., 2001; TITON et al., 2002). Rotundo (1993) aplicou essa técnica em Eucalyptus citriodora e Eucalyptus cloeziana, considerados, por esse autor, de difícil propagação vegetativa, em que visava otimizar a multiplicação e o enraizamento in vitro, bem como reduzir cada etapa do processo de micropropagação.

Apesar dos poucos trabalhos na literatura sobre o Eucalyptus cloeziana, esta espécie é considerada de difícil propagação pelo enraizamento de estacas, porém de grande importância para vários segmentos da atividade florestal. Assim, o desenvolvimento de sistemas funcionais de propagação deve ser buscado pelas empresas florestais e pelas instituições de pesquisa, a fim de se obter o domínio da técnica de propagação vegetativa para essa espécie.

Dessa forma, este trabalho objetivou avaliar a eficiência da decepa da árvore, anelamento de caule e indução de brotações epicórmicas, a partir de galhos podados, na obtenção de brotações em árvores 
selecionadas de Eucalyptus cloeziana de diferentes idades, bem como analisar a utilização de diferentes dosagens de AIB (ácido indolbutírico) no enraizamento de estacas, visando à propagação vegetativa dessa espécie pela estaquia.

\section{MATERIAL E MÉTODOS}

\subsection{Material experimental}

Este experimento foi conduzido no Viveiro de Produção de Mudas e em plantios comerciais de Eucalyptus cloeziana da Companhia Agrícola e Florestal Santa Bárbara (CAF), no Município de Bom Despacho, MG. Esse município está localizado na região Centro Oeste, na Zona do Alto São Francisco, no Estado de Minas Gerais, a uma altitude média de 768,1 m. Apresenta clima do tipo Cwa (subtropical, chuvoso e mesotérmico), segundo a classificação de Köeppen, latitude de 1944'11" S e longitude de 45 15 '08" W. A precipitação média anual da cidade é de $1230 \mathrm{~mm}$, com temperatura média anual de $22,1^{\circ} \mathrm{C}$, sendo a máxima de $29,2^{\circ} \mathrm{C}$ e mínima de $16,4^{\circ} \mathrm{C}$.

Foram utilizadas estacas obtidas a partir de brotações de cepas, de anelamento de caule e de galhos podados de árvores selecionadas em plantio comercial de Eucalyptus cloeziana localizadas em Bom Despacho, MG, conforme metodologia descrita a seguir.

\subsection{Metodologia}

\subsubsection{Resgate de árvores selecionadas de Eucalyptus cloeziana por brotações de cepas}

Árvores de Eucalyptus cloeziana de 5 e 15 anos de idade foram selecionadas e decepadas para proporcionar a emissão de brotações e, posteriormente, utilizá-las na obtenção de estacas (Figura 1). As respectivas cepas encontravam-se em pleno sol decorrente do corte raso da área de plantio. Foram utilizadas três (5C1, 5C2 e 5C3) e cinco (15C4, 15C5, $15 \mathrm{C} 6,15 \mathrm{C} 7$ e $15 \mathrm{C} 8$ ) matrizes de 5 e 15 anos de idade, respectivamente.

Após a coleta das estacas provenientes das brotações das cepas das árvores selecionadas, foram avaliados os efeitos das dosagens de 0, 1.500, 3.000 e $6.000 \mathrm{mg} \mathrm{L}^{-1}$ do regulador de crescimento AIB em pó (dissolvido em álcool e solubilizado em talco inerte) no enraizamento de estacas de E. cloeziana de 15 anos de idade, assim como as dosagens de 0 e $6.000 \mathrm{mg}$
$\mathrm{L}^{-1}$ de $\mathrm{AIB}$ nas estacas provenientes de árvores de 5 anos de idade.

As estacas de 8 a $10 \mathrm{~cm}$ de tamanho tiveram aproximadamente $1 \mathrm{~cm}$ de sua base imergida no pó auxínico e foram, imediatamente, estaqueadas em tubetes contendo substrato. O substrato utilizado foi composto por $35 \%$ de casca de Pinus decomposta, 35\% de vermiculita e $30 \%$ de casca de arroz carbonizada. Para cada 200 litros dessa mistura de substratos, foram aplicados $3 \mathrm{~L}$ de uma solução com a seguinte constituição: superfosfato simples $\left(6 \mathrm{~kg} \mathrm{~m}^{-3}\right)$, sulfato de amônio $(0,6$ $\left.\mathrm{kg} \mathrm{m}^{-3}\right)$, cloreto de potássio $\left(0,25 \mathrm{~kg} \mathrm{~m}^{-3}\right)$ e solução de sulfato de zinco $\left(18,75 \mathrm{~g} \mathrm{~m}^{-3}\right)$, sulfato de cobre $(5,63$ $\left.\mathrm{g} \mathrm{m}^{-3}\right)$, ácido bórico $\left(5,63 \mathrm{~g} \mathrm{~m}^{-3}\right)$, sulfato de manganês $\left(11,25 \mathrm{~g} \mathrm{~m}^{-3}\right)$, fetrilon $\left(20,7 \mathrm{~g} \mathrm{~m}^{-3}\right)$ e molibdato de sódio $\left(0,75 \mathrm{~g} \mathrm{~m}^{-3}\right)$.
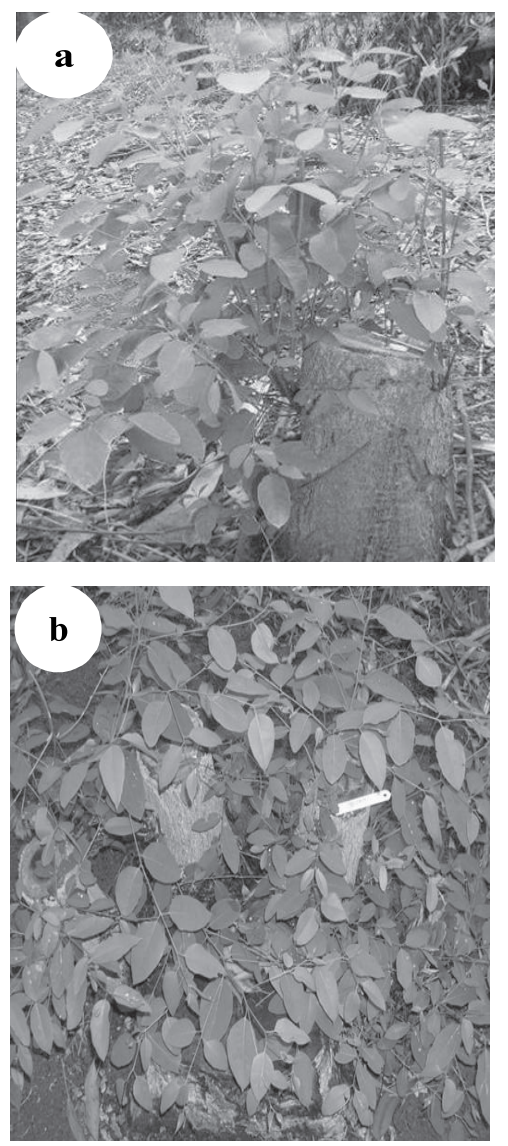

Figura 1 - Brotações de cepas com 40 dias após o corte das árvores selecionadas de Eucalyptus cloeziana aos 5 (a) e 15 (b) anos de idade.

Figure 1 - Stump shoots 40 days after cutting Eucalyptus cloeziana trees of 5 (a) and 15 (b) years old.

R. Árvore, Viçosa-MG, v.31, n.3, p.445-453, 2007 
Após inseridas no substrato, as estacas permaneceram 30 dias na casa de vegetação; em seguida, foram transferidas para a casa de sombra por um período de 10 dias e, por último, para o pátio de rustificação em pleno sol. As práticas culturais referentes a irrigação, nutrição e controle fitossanitário foram aquelas adotadas pela empresa no seu processo de produção de mudas de clones comerciais, objetivando à obtenção de mudas vigorosas.

Os experimentos foram instalados seguindo-se o delineamento inteiramente casualizado, em arranjo fatorial 3 × 2 (três árvores selecionadas e duas doses de AIB), para as árvores de 5 anos de idade e em arranjo fatorial 5 x 4 (cinco árvores selecionadas e quatro doses de AIB) para as árvores de 15 anos de idade, ambos com quatro repetições, sendo cada parcela constituída por 10 estacas. As avaliações constaram da sobrevivência das estacas na saída da casa de vegetação (SCV), porcentual de enraizamento na saída da casa de sombra (ECS) e sobrevivência (SOB90) e altura (ALT90) das mudas aos 90 dias de idade.

\subsubsection{Resgate de árvores selecionadas de Eucalyptus cloeziana por anelamento de caule}

Para a avaliação do resgate de árvores selecionadas de E. cloeziana no campo por anelamento de caule, foram selecionadas árvores de 5, 15 e 20 anos de idade, sendo o anelamento realizado em seis matrizes de cada idade. $\mathrm{O}$ anelamento consistiu na retirada de um anel de casca em torno da circunferência do tronco de aproximadamente $2 \mathrm{~cm}$ de largura, a uma altura de 15 cm do solo, até o rompimento da casca sem, contudo, danificar o lenho.

A partir das árvores que emitiram brotações, foram coletados ramos e, destes, obtidas estacas para avaliação do enraizamento adventício. As avaliações constaram da capacidade de emissão de brotações nas matrizes aneladas em cada idade e da capacidade de enraizamento das estacas obtidas a partir das brotações emitidas, conforme tratamentos apresentados no item 2.2.1.

\subsubsection{Resgate de árvores selecionadas de Eucalyptus cloeziana por galhos podados}

Para a avaliação do resgate de árvores selecionadas de E. cloeziana no campo, por indução de brotações em galhos podados, foram utilizados galhos provenientes de árvores de 20 anos de idade. Os galhos retirados foram aqueles situados na posição mais baixa da copa, para minimizar os efeitos da idade ontogenética.
Os galhos podados foram seccionados para um tamanho de aproximadamente 1 metro de comprimento, tendo suas extremidades protegidas com saco plástico para evitar perda de água e colocados em condições de casa de vegetação sobre um suporte para a indução de brotações epicórmicas (Figura 2).

As brotações emitidas foram coletadas para a confecção de estacas e colocadas para enraizamento adventício. As avaliações constaram da capacidade de emissão de brotações nos galhos podados e da capacidade de enraizamento das brotações emitidas, utilizando-se os mesmos tratamentos apresentados no item 2.2.1. Os dados obtidos foram analisados por meio do desvio-padrão da média, análise de variância e curvas de tendência.

\section{RESULTADOS E DISCUSSÃO}

\subsection{Resgate por brotações de cepas}

Em relação ao resgate por brotações de cepas em árvores de Eucalyptus cloeziana de 5 anos de idade, pôde-se perceber, independentemente das dosagens de AIB estudadas, uma sobrevivência máxima das estacas na saída da casa de vegetação, as quais se apresentara com bom vigor fisiológico (Quadro 1). Com relação ao enraizamento na saída da casa de sombra, podese observar alto índice superior $90 \%$ de enraizamento adventício das estacas. Ao verificar os dados referentes à sobrevivência das mudas aos 90 dias de idade, apesar da diminuição dos valores obtidos na saída da casa de sombra, notou-se que nessas condições estudadas, para esses materiais genéticos, as três árvores apresentaram bom potencial de enraizamento. Em relação aos dados de altura das mudas aos 90 dias de idade, observou-se diferença significativa somente nos clones (Quadro 2), o que reforça a importância do efeito do material genético na propagação vegetativa (CHALFUN, 1989; ZOBEL, 1993).

No resgate de árvores de 15 anos de idade, observou-se efeito significativo, pelo teste $\mathrm{F}(\mathrm{P}<0,05)$, da interação AS x AIB sobre todas as características analisadas, sobrevivência das estacas na saída da casa de vegetação, enraizamento na saída da casa de sombra, sobrevivência e altura das mudas aos 90 dias (Quadro 3). Excetuando-se a característica altura das mudas aos 90 dias de idade, observaram-se também diferenças significativas entre as árvores selecionadas e entre doses de AIB. 


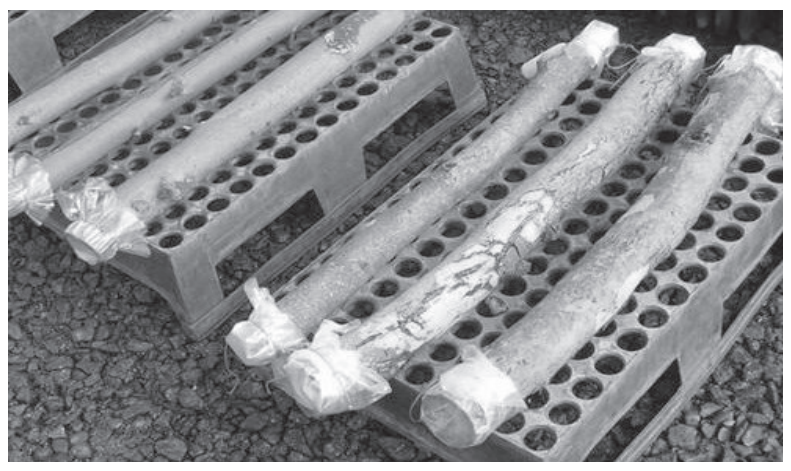

Figura 2 - Galhos podados de árvores de E. cloeziana acondicionados em condições de casa de vegetação.

Figure 2 - Pruned branches of E. cloeziana trees kept under greenhouse conditions.

Ao observar os dados referentes ao porcentual de sobrevivência na casa de vegetação e enraizamento na saída da casa de sombra (Figura 3ab), notouse resposta diferenciada dos clones em relação aos tratamentos utilizados. No clone $15 \mathrm{C} 4$, pôdese perceber uma tendência de resposta mais positiva ao enraizamento com a utilização do regulador de crescimento, uma vez que o porcentual mais baixo se deu na ausência do AIB. Nos clones $15 \mathrm{C} 5$ e $15 \mathrm{C} 8$, o regulador de crescimento não teve grande efeito no enraizamento, uma vez que não apresentaram grandes variações nos porcentuais de sobrevivência, em relação às dosagens de AIB estudadas. Os clones $15 \mathrm{C} 6$ e $15 \mathrm{C} 7$ exibiram valores máximos de sobrevivência das estacas na saída da casa de vegetação; no clone $15 \mathrm{C} 6$, esses índices ocorreram independentemente das dosagens de AIB aplicadas e, no clone 15C7, os valores máximos se deram com a aplicação de AIB.

Quadro 1 - Valores de sobrevivência das estacas na saída da casa de vegetação (SCV), enraizamento na saída da casa de sombra (ECS), sobrevivência (SOB90) e altura (ALT90) das mudas aos 90 dias de idade, em função da aplicação de ácido indolbutírico (AIB) em estacas de três árvores selecionadas de Eucalyptus cloeziana com 5 anos de idade

Table 1 - Cutting survival at greenhouse exit (SVC), rooting at shade house exit (ECS), seedling survival (SOB90) and height (ALT9O) at 90 days of age as a function of indolbutiric acid (AIB) application on cuttings of three selected five-year-old E. cloeziana trees

\begin{tabular}{cccccc}
\hline Árvore & Dosagem de & \multicolumn{4}{c}{ Características avaliadas } \\
\cline { 2 - 6 } selecionada & AIB $\left(\mathrm{mg} \mathrm{L}^{-1}\right)$ & $\mathrm{SCV}(\%)$ & $\mathrm{ECS}(\%)$ & $\mathrm{SOB} 90(\%)$ & ALT90 $(\mathrm{cm})$ \\
\hline $5 \mathrm{C} 1$ & 0 & $100,0(0)$ & $97,5(5,0)$ & $82,5(9,6)$ & $5,8(1,5)$ \\
& 6000 & $100,0(0)$ & $90,0(14,1)$ & $65,0(25,2)$ & $4,6(1,1)$ \\
$5 \mathrm{C} 2$ & 0 & $100,0(0)$ & $100,0(0)$ & $87,5(9,6)$ & $9,4(1,2)$ \\
& 6000 & $100,0(0)$ & $97,5(5,0)$ & $90,0(14,2)$ & $10,7(1,1)$ \\
$5 \mathrm{C} 3$ & 0 & $100,0(0)$ & $100,0(0)$ & $92,5(5,0)$ & $8,9(1,5)$ \\
& 6000 & $100,0(0)$ & $97,5(5,0)$ & $85,0(12,9)$ & $8,0(1,3)$ \\
\hline
\end{tabular}

Valores entre parênteses representam o desvio-padrão dos dados em torno da média.

Quadro 2 - Resultado da análise de variância das características de sobrevivência das estacas na saída da casa de vegetação (SCV), enraizamento na saída da casa de sombra (ECS), sobrevivência (SOB90) e altura (ALT90) das mudas aos 90 dias de idade, nas árvores selecionadas de Eucalyptus cloeziana de 5 anos de idade

Table 2 - Variance analysis for cutting survival characteristics at greenhouse exit (SVC), rooting at shade house exit (ECS), seedling survival (SOB90) and height (ALT90) at 90 days of age, for the selected 5-year-old E. cloeziana trees

\begin{tabular}{|c|c|c|c|c|c|}
\hline \multirow[t]{2}{*}{ FV } & \multirow[t]{2}{*}{ GL } & \multicolumn{4}{|c|}{ Quadrado Médio } \\
\hline & & $\operatorname{SCV}(\%)$ & $\operatorname{ECS}(\%)$ & SOB90 $(\%)$ & ALT90 $(\mathrm{cm})$ \\
\hline Árvore selecionada (AS) & 2 & - & $66,7^{\mathrm{ns}}$ & $600,0^{\mathrm{ns}}$ & $49,898 * *$ \\
\hline AIB & 1 & - & $104,2^{\text {ns }}$ & $337,5^{\mathrm{ns}}$ & $0,312^{\mathrm{ns}}$ \\
\hline AS $\times$ AIB & 2 & - & $16,7^{\mathrm{ns}}$ & $200,0^{\mathrm{ns}}$ & $3,674^{\mathrm{ns}}$ \\
\hline Resíduo & 18 & - & 45,8 & 201,4 & 1,661 \\
\hline Média Geral & & 100,0 & 97,08 & 83,75 & 7,90 \\
\hline CV exp. (\%) & & & 6,97 & 16,95 & 16,31 \\
\hline
\end{tabular}

$\mathrm{ns}=$ não-significativo, $*$ e $* *$ significativos a $5 \%$ e $1 \%$ de probabilidade, respectivamente, pelo teste $\mathrm{F}$. 
Quadro 3 - Resultado da análise de variância das características de sobrevivência das estacas na saída da casa de vegetação (SCV), enraizamento na saída da casa de sombra (ECS), sobrevivência (SOB90) e altura (ALT90) das mudas aos 90 dias de idade, nas árvores selecionadas de Eucalyptus cloeziana de 15 anos de idade

Table 3 -Variance analysis for cutting survival characteristics at greenhouse exit (SVC), rooting at shade house exit (ECS), seedling survival (SOB90) and height (ALT90) at 90 days of age, for the selected 15-year-old E. cloeziana trees

\begin{tabular}{cccccc}
\hline FV & GL & \multicolumn{3}{c}{ Quadrado Médio } \\
\cline { 2 - 6 } & & SCV $(\%)$ & ECS $(\%)$ & SOB90 $(\%)$ & ALT90 $(\mathrm{cm})$ \\
\hline Árvore selecionada (AS) & 4 & $4531,3^{* *}$ & $22475,0^{* *}$ & $6648,1^{* *}$ & $8,7^{\mathrm{ns}}$ \\
AIB & 3 & $1264,6^{* *}$ & $2143,7^{*}$ & $2823,3^{* *}$ & $18,4^{\mathrm{ns}}$ \\
AS x AIB & 12 & $2489,6^{* *}$ & $27325,0^{* *}$ & $1947,3^{* *}$ & $56,9^{* *}$ \\
Resíduo & 60 & 223,8 & $247,1,0$ & 467,5 & 8,8 \\
\hline Média Geral & & 78,13 & 75,6 & 33,0 & 4,4 \\
\hline CV $_{\text {exp. }}(\%)$ & & 19,2 & 20,8 & 65,5 & 67,7 \\
\hline
\end{tabular}

$\mathrm{ns}=$ não-significativo, $* \mathrm{e}^{* *}$ significativos a $5 \%$ e $1 \%$ de probabilidade, respectivamente, pelo teste $\mathrm{F}$.

a)
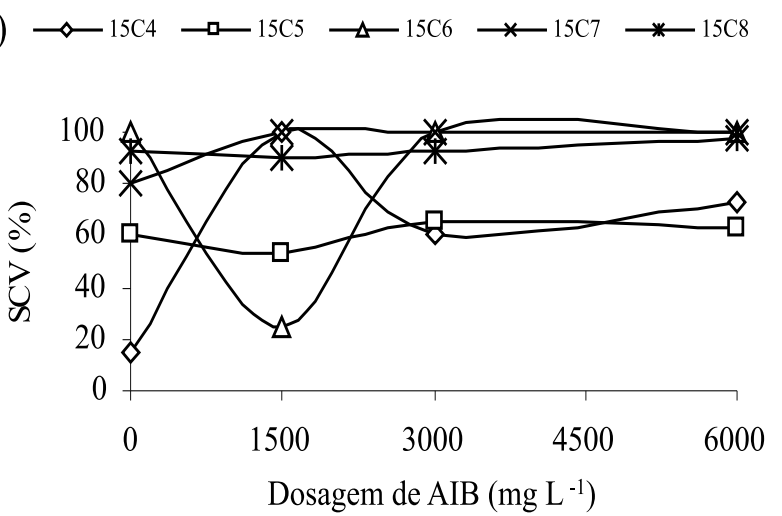

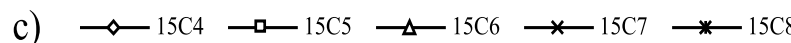

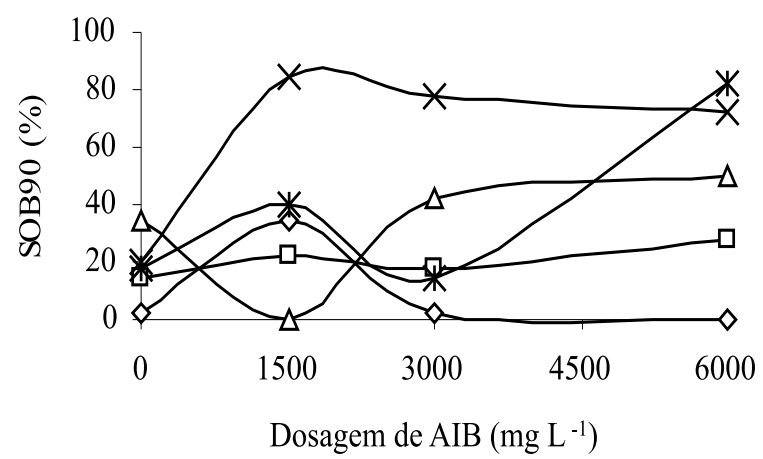

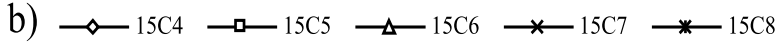

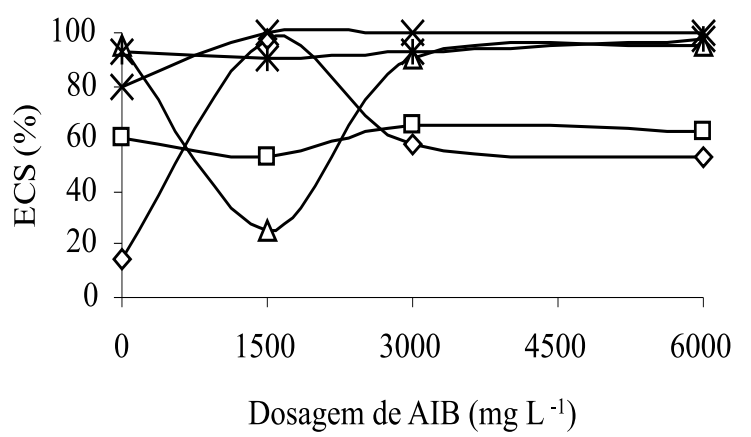

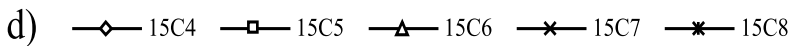

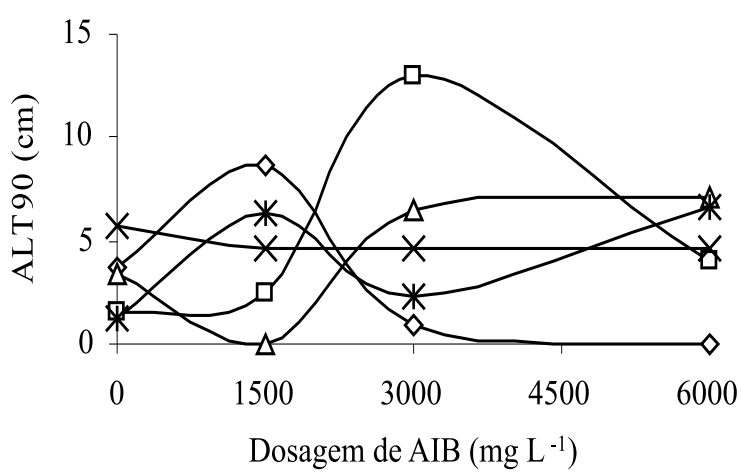

Figura 3 - (a) Sobrevivência das estacas na saída da casa de vegetação (SCV), (b) enraizamento na saída da casa de sombra (ECS), (c) sobrevivência (SOB90) e (d) altura das mudas (ALT90) aos 90 dias de idade, em resposta à aplicação de AIB (0, 1.500, 3.000 e $\left.6.000 \mathrm{mg} \mathrm{L}^{-1}\right)$, nas cinco árvores selecionadas de Eucalyptus cloeziana de 15 anos de idade.

Figure 3 - (a) Cutting survival at greenhouse exit (SVC), (b) rooting at shade house exit (ECS), (c) seedling survival (SOB90) and (d) height (ALT90) at 90 days of age in response to IBA application (0, 1500,3000 and $\left.6000 \mathrm{mg} / \mathrm{L}^{-1}\right)$, for the five selected 15 year old E. cloeziana trees.

R. Árvore, Viçosa-MG, v.31, n.3, p.445-453, 2007 
Esses resultados traduzem que as matrizes de 5 anos de idade apresentaram melhores respostas aos índices de sobrevivência na saída da casa de vegetação, sem a aplicação do regulador de crescimento (Quadro 1), em relação às matrizes de 15 anos de idade. Esse melhor comportamento dos clones de 5 anos de idade, em relação aos de 15 anos, pode estar, principalmente, associado aos efeitos da idade ontogenética (WENDLING e XAVIER, 2001), a diferenças do material genético (CHALFUN, 1989; ZOBEL, 1993) e a condições ambientais.

Na avaliação da sobrevivência das mudas aos 90 dias de idade (Figura 3c), de modo geral, em alguns clones, houve redução acentuada no porcentual de enraizamento. O clone $15 \mathrm{C} 4$ foi o que apresentou os piores índices de sobrevivência aos 90 dias, tendo seu valor máximo de $35 \%$ de estacas enraizadas com a aplicação de $1.500 \mathrm{mg} \mathrm{L}^{-1} \mathrm{de}$ AIB, chegando a valores como $2,5 \%$ para AIB $3000 \mathrm{mg} \mathrm{L}^{-1}$ e até a sobrevivência nula na aplicação de AIB $6.000 \mathrm{mg} \mathrm{L}^{-1}$. Os melhores porcentuais de sobrevivência das mudas aos 90 dias de idade foram observados nos clones $15 \mathrm{C} 7$ e $15 \mathrm{C} 8$. No clone $15 \mathrm{C} 7$, verificaram-se respostas positivas das mudas quando as estacas foram tratadas com AIB, chegando a atingir até $85 \%$ de sobrevivência no tratamento com AIB $1.500 \mathrm{mg} \mathrm{L}^{-1}$. Já o clone $15 \mathrm{C} 8$ apresentou o maior porcentual de sobrevivência $(82,5 \%)$ quando tratado com AIB $6.000 \mathrm{mg} \mathrm{L}^{-1}$.

Vale salientar que, neste trabalho, os gráficos foram elaborados a partir das médias das características, pois os coeficientes de determinação $\left(\mathrm{R}^{2}\right)$, na análise de regressão, apresentaram valores muito baixos. Isso denota não-confiabilidade das equações de regressão para explicar as respostas das características avaliadas em função das aplicações de AIB.

O comportamento menos eficiente dos clones de 15 anos de idade, em relação aos de 5 anos, pode estar relacionado ao envelhecimento ontogenético (ASSIS, 1997), o qual influencia diretamente os índices de enraizamento adventício. Geralmente, brotações provenientes de árvores mais juvenis apresentam maior facilidade de enraizamento, enquanto estacas provenientes de árvores mais velhas o fazem esporadicamente ou, definitivamente, não enraízam (ZOBEL e TALBERT, 1984).

Diante desses resultados, pode-se perceber que houve variação de resposta entre os clones no que se refere ao potencial rizogênico, apresentando alguns clones melhor resposta ao enraizamento quando submetidos a tratamentos com o AIB. Ocorreu também nítida diferença de comportamento entre os clones de 5 e 15 anos de idade, apresentando os clones de 5 anos maior predisposição ao enraizamento adventício que os de 15 anos de idade.

\subsection{Resgate por galhos podados e anelamento de caule}

O resgate por galhos podados mostrou ser uma técnica eficiente na indução de brotações epicórmicas de árvores de Eucalyptus cloeziana, uma vez que todos os galhos podados que se encontravam na casa de vegetação emitiram brotações após 40 dias de acondicionamento, como se pode observar na Figura 4. Porém, as estacas extraídas dessas brotações não responderam ao enraizamento adventício. Entre os possíveis fatores, o efeito da idade ontogênica e o vigor fisiológico das estacas utilizadas provavelmente foram determinantes, visto que a coleta dos galhos se deu em árvores com 20 anos de idade e, por mais que se priorizasse a retirada de galhos mais baixos dessas árvores, estes foram extraídos em alturas acima de $5 \mathrm{~m}$. Considerando que existe um gradiente de juvenilidade em direção à base da árvore e que a capacidade de enraizamento é uma característica juvenil (ZOBELe TALBERT, 1984; HACKETT, 1988), os galhos retirados seriam ontogeneticamente adultos e, portanto, com menor capacidade de enraizamento adventício de estacas em relação aos mais juvenis.

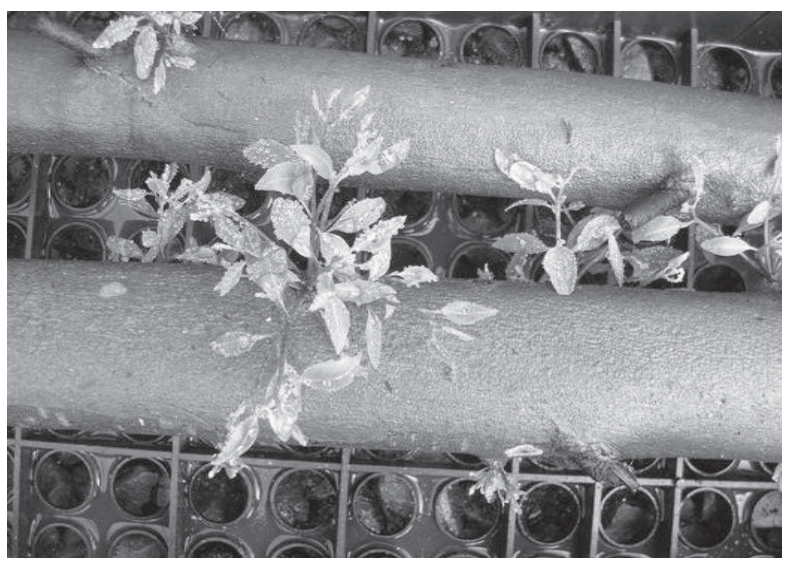

Figura 4-Galhos podados de árvores de Eucalyptus cloeziana de 20 anos de idade, apresentando emissão de brotações epicórmicas.

Figure 4-Pruned branches of 20-year-old E. cloeziana trees showing epicormic shoot emission.

R. Árvore, Viçosa-MG, v.31, n.3, p.445-453, 2007 
Quanto ao anelamento de caule (Figura 5), pôdese observar, nas árvores de 5 e 15 anos de idade, intensa cicatrização da parte anelada como resposta à aplicação do anelamento; porém, não se observou emissão de brotação epicórmica nessa região. As árvores com 20 anos de idade também mostraram intenso calejamento na região anelada; no entanto, foram verificadas brotações epicórmicas em duas das seis árvores aneladas (Figura 5c). As estacas extraídas dessas brotações não responderam ao enraizamento adventício. Segundo Alfenas et al. (2004), a capacidade de brotação da matriz pode variar de acordo com o genótipo da planta, a época do ano, a luminosidade e a espessura e a profundidade do corte, assim como o enraizamento adventício é função de fatores genéticos e fisiológicos, entre outros.

As duas técnicas utilizadas no resgate de árvores selecionadas para a clonagem mostraram-se eficientes na emissão de brotações. Porém, como a formação de raízes adventícias em estacas é um processo complexo, que pode ser influenciado por diversos fatores, como idade, estado nutricional e hídrico da planta doadora de propágulos, balanço hormonal, constituição genética, local de coleta dos galhos e de aplicação do anelamento, entre outras, as brotações coletadas para a extração de estacas não apresentaram potencial rizogênico.
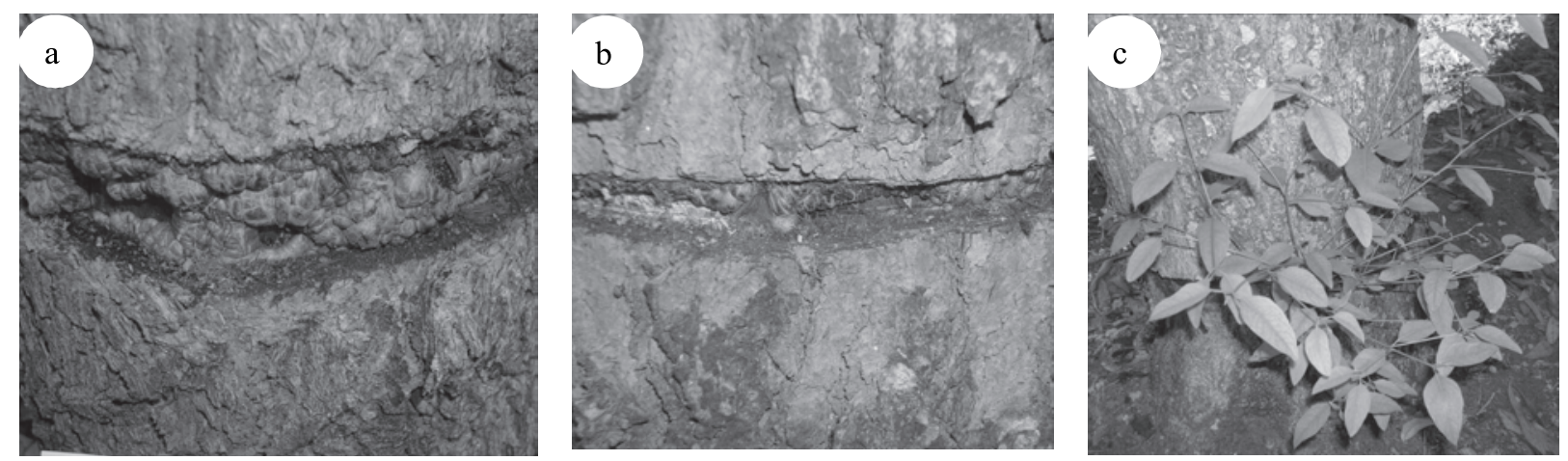

Figura 5 - Respostas de árvores de Eucalyptus cloeziana com 5 (a), 15 (b) e 20 (c) anos de idade, após 60 dias da aplicação do anelamento.

Figure 5 - Responses of $5(a)$ and $15(b)$ and $20($ b) year old E. cloeziana trees, 60 days after ringing.

\section{CONCLUSÕES}

Os resultados evidenciaram que o resgate de árvores selecionadas de Eucalyptus cloeziana por brotações de cepas é uma técnica com potencial para a clonagem dessa espécie, principalmente de árvores selecionadas em idades mais juvenis.

A avaliação do resgate por anelamento de caule e por indução de brotações epicórmicas, em galhos podados, indicou que essas duas técnicas apresentam potencial para a indução de brotações, porém o enraizamento adventício das estacas extraídas dessas brotações necessita de mais estudos.

\section{AGRADECIMENTOS}

À Companhia Agrícola e Florestal Santa Bárbara (CAF), pela disponibilização do material experimental e estrutural na condução da pesquisa; e ao Conselho
Nacional de Pesquisa e Desenvolvimento Científico e Tecnológico (CNPq), pelo suporte financeiro.

\section{REFERÊNCIAS}

Alfenas, A. C. et al. Clonagem e doenças do eucalipto. Viçosa, MG: Universidade Federal de Viçosa, 2004. 442 p.

ASSIS, T. F. Propagação vegetativa de Eucalyptus por microestaquia. In: IUFRO CONFERENCE ON SILVICULTUREANDIMPROVEMENTOS

EUCALYPTS, 1997, Salvador. Proceedings... Colombo: Embrapa, 1997. v.1.p.300-304.

ASSIS, T. F.; ROSA, O. P.; GONÇALVES, S. I. Propagação por microestaquia. In: CONGRESSO FLORESTAL ESTADUAL, 7., 1992, Nova Prata. Anais... Santa Maria: Universidade Federal de Santa Maria, 1992. p.824-836. 
ASSIS, T. F.; TEIXEIRA, S. L. Enraizamento de plantas lenhosas. In: TORRES, A. C.; CALDAS, L. S.; BUSO, J. A. (Ed.). Cultura de tecidos e transformação genética de plantas. Brasília: Embrapa-SPI/Embrapa-CNPH, 1998. p.261-296.

BONGA, J. M.; von ADERKAS, P. In vitro culture of trees. Nertherlands: Kluwer Academic Publishers, 1992. 236p.

CHALFUN, N. N. J. Fatores bioquímicos e fisiológicos no enraizamento de estacas de Hibiscus rosa-sinensis L. 1989. 85f. Tese (Doutorado em Fitotecnia) Departamento de Fitotecnia, Universidade Federal de Viçosa, Viçosa, MG, 1989.

FACHINELLO, J. C. Efeitos morfofisiológicos do anelamento no enraizamento de estacas lenhosas de macieira cultivar Malling-Merton 106. 1986. 93f. Tese (Doutorado em Agronomia) - Escola Superior de Agricultura Luís de Queiroz, Piracicaba, 1986.

HACKETT, W. P. Donnor plant maturation. In: DAVIES, T. D.; HAISSIG, B. E. (Ed.). Adventitious root formation in cuttings. Portland: Dioscorides Press, 1988. p.11-28.

HACKETT, W. P.; MURRAY, J. R. Maturation and rejuvenation in woody species. In: AHUJA, M. R. (Ed.). Micropropagation of $\operatorname{woody}$ plants. Dordrecht: Kluwer Academic Publishers, 1993. p.93-105.
ROTUNDO, C. C. Efeitos de concentrações de nitrato de amônio na multiplicação e no enraizamento "in vitro" de clones Eucalyptus cloeziana F. Muell e Eucalyptus citriodora Hook. 1993. 74f. Dissertação (Mestrado em Ciências Florestais) Universidade de São Paulo, São Paulo, 1993.

TITON, M.; XAVIER, A.; OTONI, W. C. Dinâmica do enraizamento de microestacas e miniestacas de clones de Eucalyptus grandis. Revista Árvore, v.26, n.6, p.665-673, 2002.

WENDLING, I.; XAVIER, A. Gradiente de maturação e rejuvenescimento aplicado em espécies florestais. Floresta e Ambiente, v.8, n.1, p.187-194, 2001.

XAVIER, A. Silvicultura clonal I:

Princípios e técnicas de propagação vegetativa. Viçosa, MG: Universidade Federal de Viçosa. 2002. 64p. (Cadernos Didáticos).

XAVIER, A.; COMÉRIO, J. Microestaquia: uma maximização da micropropagação de Eucalyptus. Revista Árvore, v.20, n.1, p.9-16, 1996.

XAVIER, A. et al. Desempenho do enraizamento de microestacas e miniestacas de clones híbridos de Eucalyptus grandis. Revista Árvore, v.25, n.4, p.403-411, 2001.

ZOBEL, B. J. Clonal forestry in the eucalypts. In: AHUJA, M. R.; LIBBY, W. J. (Ed.). Clonal forestry: conservation and application. Budapest: Springer-Verlag, 1993. p.139-148.

ZOBEL, B.; TALBERT, J. Applied forest tree improvement. New York: Wiley \& Sons, 1984. 505p. 
